\title{
University Environment and Global Citizenship Identification
}

\author{
Marion E. Blake ${ }^{1}$, Lindsey Pierce ${ }^{2}$, Shonda Gibson ${ }^{2}$, Stephen Reysen ${ }^{2}$ \& Iva Katzarska-Miller ${ }^{3}$ \\ ${ }^{1}$ Texas A\&M University-Kingsville, Kingsville, Texas, United States \\ ${ }^{2}$ Texas A\&M University-Commerce, Commerce, Texas, United States \\ ${ }^{3}$ Transylvania University, Lexington, Kentucky, United States \\ Correspondence: Marion E Blake, Department of Psychology \& Sociology, Texas A\&M University-Kingsville, \\ Kingsville, Texas, United States. Tel: 1-361-593-2328. E-mail: Marion.Blake@tamuk.edu
}

Received: November 4, 2014

Accepted: December 13, $2015 \quad$ Online Published: April 9, 2015

doi:10.5539/jedp.v5n1p97

URL: http://dx.doi.org/10.5539/jedp.v5n1p97

\begin{abstract}
We examined the influence of the university environment (Study 1), and specific college courses (Study 2), on the antecedents and outcomes of global citizenship identification. In Study 1, participants' perception of the university environment as prescribing a global citizen identity predicted the perception of one's normative environment as prescribing this identity and global awareness (antecedents) leading to greater identification with global citizens. Global citizenship identification then predicted greater endorsement of prosocial values and behaviors (outcomes). In Study 2, participants' perception of a class as encouraging greater global understanding influenced the antecedents, global citizenship identification, and its outcomes. The results highlight the importance of a university setting as a normative environment for development of global citizenship identification and related prosocial values.
\end{abstract}

Keywords: global awareness, global citizenship, normative environment, prosocial values

\section{Introduction}

Globalization has increased cross-cultural interaction and global interdependence through the widespread use of media, information and communication technology, world travel, and international trade (Gelfand, Lyons, \& Lun, 2011). As a result, governments, businesses, and educators have called on schools (e.g., colleges and universities) to prepare students to function effectively in globalized economies (Gacel-Avila, 2005; Spring, 2008) and multicultural societies (Dower, 2008; Gollnick \& Chinn, 2013; Merryfield, Lo, Po, \& Kasai, 2008; Pike, 2008). Global citizenship education has been championed as a vehicle for accomplishing this goal through fostering global citizenship identification (Pike, 2008). Past theorizing on global citizenship suggests that identifying as a global citizen is related to beneficial outcomes such as prosocial values (Dower, 2008; Oxfam, 1997; Schattle, 2008). Indeed, empirical research (e.g., Reysen \& Katzarska-Miller, 2013a; Reysen, Larey, \& Katzarska-Miller, 2012) has identified a number of prosocial outcomes consistently associated with viewing oneself as being a global citizen (e.g., valuing diversity, intergroup empathy). Building upon recent advances in understanding a global citizen identity, the present studies investigate the influence of one's educational environment on antecedents, identification, and outcomes of global citizenship.

\subsection{Global Citizen Identity}

Throughout daily social interactions, individuals frequently behave as members of a group, rather than as individuals (Tajfel \& Turner, 1979). Following a social identity perspective (Tajfel \& Turner, 1979; Turner, Hogg, Oakes, Reicher, \& Wetherell, 1987), when a social identity is adopted, greater ingroup identification (i.e., felt connectedness to the group) predicts adherence to a group's prescribed norms (e.g., beliefs, values, behaviors). Recently, Reysen, Pierce, Spencer, and Katzarska-Miller (in press) conducted a series of studies to investigate the content and behavioral norms theorized to be related to global citizenship. The results show that global citizenship identification is uniquely related to prosocial values and behaviors, whereas the norms associated with other identities (i.e., human, American) are not. In other words, the identity—global citizen —is associated with an interrelated set of prosocial values and behaviors. When the identity is salient, greater identification is related to a greater likelihood that individuals will endorse and enact the values and behaviors reflecting the content of the group. 
In subsequent studies, Reysen and Katzarska-Miller (2013a) developed and tested a model of antecedents and outcomes related to identification with this group. The model suggests that one's normative environment (i.e., persons and environments that cue and prescribe a global citizen identity) and global awareness (i.e., knowledge about the world and a sense of human interconnectedness) predict global citizenship identification. In turn, global citizenship identification predicts prosocial outcomes, including intergroup empathy (i.e., felt connection to others outside one's in group), valuing diversity (e.g., interest and appreciation for diverse cultures), social justice (e.g., endorsement of human rights and equality), environmental sustainability (e.g., concern for the natural environment), intergroup helping (i.e., desire to help others outside one's in group), and felt responsibility to act for the betterment of the world. Although this model has been replicated in subsequent research (Plante, Roberts, Reysen, \& Gerbasi, 2014; Reysen, Katzarska-Miller, Gibson, \& Hobson, 2013; Reysen et al., 2012), further research is needed to examine aspects of one's socio-cultural environment that may influence the model.

\subsection{Education and Global Citizenship}

Consistent with the notion of intentional worlds (Shweder, 1990), and the mutual constitution conception of culture (see Adams \& Markus, 2004), everyday settings (e.g., home, school, work) containing individuals, artifacts (e.g., media, organizations), or cultural patterns that reflect and encourage global citizenship may cultivate global citizenship identification in those who engage those settings (Katzarska-Miller, Reysen, Kamble, \& Vithoji, 2012; Plante et al., 2014; Reysen \& Katzarska-Miller, 2013b). Theorists suggest that the socio-cultural environment of school is an influential part of students' development of global citizenship (Pike, 2008; Schattle, 2008; Young \& Commins, 2002). For instance, educational settings contain faculty, administrators, organizations, programs, curricula, diverse students, and artifacts (e.g., wall displays) that can prime and condition a globally oriented perspective. Research on the influence of university instruction revealed that how university administrators discuss globalization (Snider, Reysen, \& Katzarska-Miller, 2013) and how professors frame the concept of global citizenship for students (Gibson \& Reysen, 2013) influences students' degree of identification with global citizens. However, beyond individuals in one's immediate environment (e.g., faculty), settings may also contain socio-cultural patterns (Reysen \& Levine, 2014) that encourage global citizen identity (e.g., recycling programs, study abroad, international awareness activities). In other words, the school environment, in general, may have the potential to encourage global citizen identification by priming the identity.

Infusing global perspectives within the school curriculum has also been identified as a key component to increasing students' global knowledge and awareness of other cultures (Fujikane, 2003; Hicks, 2003) and promoting global citizenship identification among students. To examine an indirect link between a university curriculum and global citizen identification, Reysen and colleagues (2012) asked students enrolled in college courses with globally infused curriculum (operationalized as the number of global citizenship related words included in the course syllabus) to complete measures of global citizenship antecedents, identification, and outcomes at the beginning and end of a college semester. The results showed that participation in courses with globally infused curriculum predicted global awareness, which in turn predicted greater global citizenship identification and prosocial outcomes at the end of the semester. These results support the assertion that globally infused curriculum, or the content of education, can engender greater global citizenship identification (and related prosocial outcomes) by increasing students' global awareness. However, the study provided only indirect support for the link between the content of class curricula and global citizenship. A direct measure would bolster the claims that globally infused curriculum can affect global citizen identification.

\subsection{Overview of Present Research}

The purpose of the present studies was to examine the influence of one's perception of the school environment, in general, and perception of a college course's curriculum, specifically, on the model of antecedents, identification, and outcomes of global citizenship. Theorists suggest that education influences the development of global citizenship (Dower, 2008; Pike, 2008; Schattle, 2008; Spring, 2008), including both the school setting (Young \& Commins, 2002) and the curriculum (Oxfam, 1997). Indeed, research suggests that cultural settings in which individuals reside (Katzarska-Miller et al., 2012) and globally infused curriculum (Reysen et al., 2012) may influence one's degree of identification with global citizens. Extending prior theory and research, in the present studies the researchers examined the influence of the university environment in general (Study 1), and specific college course (Study 2) on the Reysen and Katzarska-Miller's (2013a) model of antecedents and outcomes of global citizenship identification. The researchers hypothesized that the environment in which 
students are embedded (university as a whole in Study 1 and a specific college class in Study 2) would influence the antecedents, identification, and outcomes of global citizenship.

\subsection{Study 1 Hypothesis}

In Study 1, the researchers predicted that students' perception of their university's normative environment as prescribing a global citizen identity would influence the antecedents, identification, and outcomes of global citizenship.

\section{Method}

\subsection{Participants and Procedure}

Participants $\left(N=1183,55.1 \%\right.$ women; $M_{\text {age }}=30.43$ years, $\left.S D=9.71\right)$ from a variety of classes (e.g., psychology, political science, marketing, English, finance, anthropology, economics, business, sociology) participated for either course credit or extra credit at Texas A\&M University-Commerce. Participants included undergraduate $(66 \%)$ and graduate $(44 \%)$ students. Participants indicated their racial/ethnic category as European American (52.5\%), African American (15\%), Hispanic (12.3\%), Asian/South Pacific Islander (9.5\%), Arab/Middle Eastern (4\%), multiracial (2.4\%), other (1.8\%), Indigenous Peoples (1.5\%), or Central Asian/Indian/Pakistani (1.1\%). The participants completed measures regarding perceptions of the university's support of global citizenship along with the antecedents, identification, and outcomes of global citizenship. Except for demographic items, all measures used a 7-point Likert-type response scale, from $1=$ strongly disagree to $7=$ strongly agree.

\subsection{Materials}

\subsubsection{University Normative Environment}

A single item ("The university encourages me to be a global citizen") assessed students' perception that the university prescribes global citizenship.

\subsubsection{Global Citizenship}

To assess the antecedents, identification, and outcomes of global citizenship, measures were adopted from Reysen and Katzarska-Miller (2013a).Two items (e.g., "Most people who are important to me think that being a global citizen is desirable") assessed the perception that others in one's normative environment prescribe a global citizen identity $(\alpha=.83)$. Four items (e.g., "I understand how various cultures of this world interact socially") assessed global awareness $(\alpha=.81)$. Two items (e.g., "I strongly identify with global citizens") assessed global citizenship identification $(\alpha=.92)$. Two items (e.g., "I am able to empathize with people from other countries") assessed intergroup empathy $(\alpha=.79)$. Two items (e.g., "I would like to join groups that emphasize getting to know people from different countries") assessed valuing diversity ( $\alpha=.83$ ). Two items (e.g., "Those countries that are well off should help people in countries who are less fortunate") assessed social justice $(\alpha=.73)$. Two items (e.g., "People have a responsibility to conserve natural resources to foster a sustainable environment") assessed environmental sustainability $(\alpha=.77)$. Two items (e.g., "If I could, I would dedicate my life to helping others no matter what country they are from") assessed intergroup helping ( $\alpha=.73$ ). Lastly, two items (e.g., "Being actively involved in global issues is my responsibility") assessed responsibility to act $(\alpha=.82)$.

\section{Results}

\subsection{Preliminary Analyses}

To examine the relationship between perception of the university environment and global citizenship, the researchers conducted zero-order correlations. As shown in Table 1, the perception of the university environment as encouraging global citizenship was positively significantly correlated with the antecedents, identification, and outcomes of global citizenship.

\subsection{Structural Equation Model}

To test the influence of perception of the university environment on the antecedents, identification, and outcomes of global citizenship, the researchers conducted a structural equation model using Amos 19 (bias-corrected bootstrapping, 5,000 iterations, $95 \%$ confidence intervals). Due to the related nature of the prosocial values to one another (and the antecedents to one another), the disturbance terms for these sets of variables were allowed to covary. Identical to Reysen and Katzarska-Miller (2013a) structural model, the error terms of two global awareness items were allowed to covary. The model fit was evaluated using the normed fit index (NFI) and the comparative fit index (CFI), for which values greater than .90 are acceptable (Hu \& Bentler, 1995). Following 
Browne and Cudeck (1993), the root mean square error of approximation (RMSEA) was set at value of .08, which is an acceptable level.

Items loaded well on each of the factors, including normative environment $(.82, .87)$, global awareness $(.52$ to .91$)$, global citizenship identification $(.91, .93)$, intergroup empathy $(.73, .88)$, valuing diversity $(.84, .86)$, social justice $(.73, .78)$, environmental sustainability $(.77, .84)$, intergroup helping $(.72, .83)$, and responsibility to act $(.81, .86)$. The predicted model adequately fit the data, $\chi^{2}(163)=1225.61, p<.001$; RMSEA $=.074$, $\mathrm{CI}\{.070 ; .078\}, \mathrm{NFI}=.920$, and $\mathrm{CFI}=.930$.

As shown in Figure 1, perception of the university environment predicted greater normative environment ( $\beta$ $=.52, p<.001, \mathrm{CI}=.458$ to .578$)$ and global awareness $(\beta=.45, p<.001, \mathrm{CI}=.380$ to .506$)$. Normative environment $(\beta=.68, p<.001, \mathrm{CI}=.621$ to .741$)$ and global awareness $(\beta=.31, p<.001, \mathrm{CI}=.241$ to .376$)$ predicted global citizenship identification. Global citizenship identification predicted intergroup empathy $(\beta$ $=.68, p<.001, \mathrm{CI}=.623$ to .729$)$, valuing diversity $(\beta=.65, p<.001, \mathrm{CI}=.594$ to .693$)$, social justice $(\beta=.53$, $p<.001, \mathrm{CI}=.461$ to .585$)$, environmental sustainability $(\beta=.54, p<.001, \mathrm{CI}=.484$ to .597$)$, intergroup helping $(\beta=.47, p<.001, \mathrm{CI}=.401$ to .527$)$, and felt responsibility to act $(\beta=.69, p<.001, \mathrm{CI}=.642$ to .737$)$.

Table 1. Correlations between perception of university normative environment and antecedents, identification, and outcomes of global citizenship, Study 1 (All correlations are significant at $p<.01$ )

\begin{tabular}{lllllllllll}
\hline Variable & 1 & 2 & 3 & 4 & 5 & 6 & 7 & 8 & 9 & 10 \\
\hline 1. University Normative & 1.0 & & & & & & & & & \\
2.Normative Environment & .47 & 1.0 & & & & & & & & \\
3. Global Awareness & .42 & .47 & 1.0 & & & & & & & \\
4. Global Citizenship & .47 & .74 & .65 & 1.0 & & & & & & \\
5. Intergroup Empathy & .32 & .42 & .55 & .57 & 1.0 & & & & \\
6. Valuing Diversity & .34 & .45 & .56 & .56 & .55 & 1.0 & & & & \\
7. Social Justice & .28 & .42 & .40 & .41 & .36 & .50 & 1.0 & & & \\
8. Environmentalism & .33 & .42 & .41 & .44 & .36 & .47 & .65 & 1.0 & & \\
9. Intergroup Helping & .27 & .35 & .41 & .40 & .41 & .53 & .54 & .56 & 1.0 & \\
10. Responsibility to Act & .38 & .48 & .58 & .58 & .49 & .62 & .51 & .57 & .62 & 1.0 \\
\hline Mean & 5.23 & 4.81 & 5.14 & 4.65 & 5.02 & 5.35 & 5.66 & 5.72 & 5.69 & 5.32 \\
Standard Deviation & 1.40 & 1.35 & 1.12 & 1.44 & 1.30 & 1.27 & 1.24 & 1.22 & 1.21 & 1.27 \\
\hline
\end{tabular}

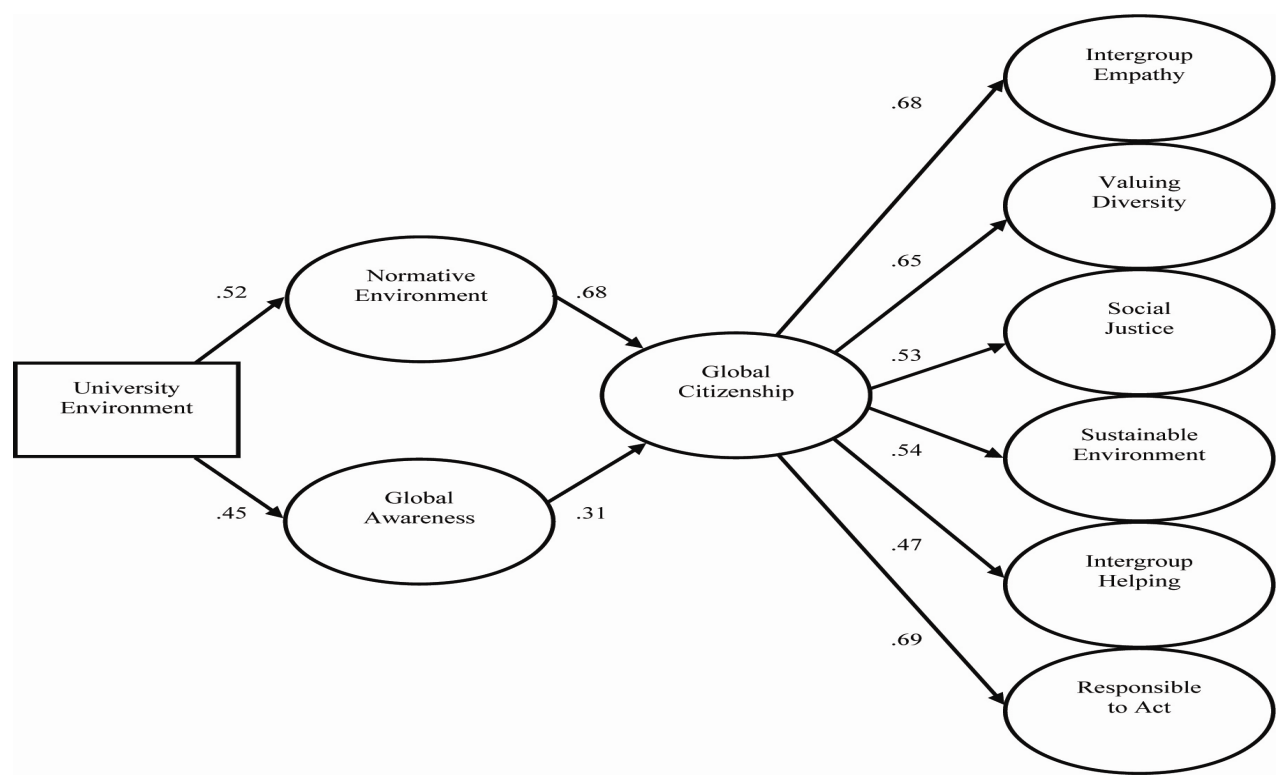

Figure 1. Influence of perception of university environment on global citizenship, Study 1(All standardized betas are significant at $p<.001$ ) 
The indirect effect of perception of the university environment was reliably carried by normative environment and global awareness on students' identification with global citizens (see Table 2 for standardized betas of indirect effects and 95\% bias-corrected confidence intervals; all indirect effects were significant at $p<.002$ two-tailed). Perception of the university environment also significantly predicted greater prosocial values through normative environment, global awareness, and global citizenship identification. The influence of normative environment and global awareness on prosocial values was reliably carried by global citizenship identification. In effect, perceiving the university environment as prescribing the identity of global citizen predicts greater normative environment and global awareness leading to greater identification with global citizens and a subsequent increase in prosocial values. We also tested the model including participants' biological sex and age as covariates. The model was largely unchanged by including these demographic variables.

Table 2.Indirect effects of university normative environment, normative environment, and global awareness, Study 1 (Standardized betas and 95\% confidence intervals, bias-corrected bootstrapping with 5,000 iterations, all indirect effects are significant at $p<.002$ )

\begin{tabular}{llllllllll}
\hline \multirow{2}{*}{ Variable } & \multicolumn{3}{l}{ University } & \multicolumn{3}{c}{ Normative } & \multicolumn{2}{l}{ Normative } & \multicolumn{3}{l}{ Global } \\
& Indirect & $\mathrm{CI}_{\text {Lower }}$ & $\mathrm{CI}_{\text {Upper }}$ & Indirect & $\mathrm{CI}_{\text {Lower }}$ & $\mathrm{CI}_{\text {Upper }}$ & Indirect & $\mathrm{CI}_{\text {Lower }}$ & $\mathrm{CI}_{\text {Upper }}$ \\
\hline Global Citizenship ID & .49 & .437 & .541 & & & & & & \\
Intergroup Empathy & .34 & .288 & .380 & .46 & .416 & .511 & .21 & .161 & .264 \\
Valuing Diversity & .32 & .273 & .363 & .44 & .396 & .488 & .20 & .154 & .252 \\
Social Justice & .26 & .517 & .304 & .36 & .310 & .412 & .16 & .122 & .207 \\
Environmentalism & .27 & .222 & .311 & .37 & .322 & .420 & .17 & .127 & .212 \\
Intergroup Helping & .23 & .188 & .271 & .32 & .270 & .368 & .14 & .108 & .186 \\
Responsibility to Act & .34 & .294 & .386 & .47 & .424 & .520 & .21 & .164 & .267 \\
\hline
\end{tabular}

\section{Discussion}

The purpose of Study 1 was to examine whether students' perception that their university encouraged global citizenship would influence the model of antecedents and outcomes of global citizenship identification. As expected, students' perception of the university environment as valuing global citizenship predicted students' normative environment and global awareness, which then predicted global citizenship identification, which subsequently predicted the prosocial outcomes (i.e., intergroup empathy, valuing diversity, social justice, environmental sustainability, intergroup helping, and felt responsibility to act). Study 2 was designed to examine the influence of a more specific aspect of the university environment (i.e., a class/course) on the model of global citizenship identification.

\section{Study 2}

\subsection{Purpose of Study 2}

The purpose of Study 2 was to examine whether students' perception that a specific college course encouraged greater global awareness would influence Reysen and Katzarska-Miller's (2013a) model of global citizenship identification. The researchers expected the students' perception that a specific college class increased their degree of global awareness would influence the model similarly to what was observed in Study 1. Past research (Reysen et al., 2013) has shown that the perception of one's own knowledge is a stronger predictor of identification with global citizens than the amount of factual knowledge one has acquired about the world. Therefore, in Study 2 the participants' perceived global awareness was assessed rather than their factual knowledge.

\section{Method}

\subsection{Participants and Procedure}

Participants $\left(N=805,61.7 \%\right.$ women; $M_{\text {age }}=27.79$ years, $\left.S D=9.86\right)$ from a variety of classes (e.g., health, agriculture, psychology, political science, marketing, English, philosophy, economics, business, sociology) participated for either course credit or extra credit at Texas A\&M University-Commerce.Participants included 
undergraduate $(95.2 \%)$ and graduate $(4.8 \%)$ students. Participants indicated their racial/ethnic category as European American (63.1\%), African American (17.3\%), Hispanic (11.3\%), multiracial (2.9\%), Indigenous Peoples (1.7\%), Asian/South Pacific Islander (1.5\%), other (1.1\%), Arab/Middle Eastern (0.6\%), or Central Asian/Indian/Pakistani (0.5\%). Participants completed measures regarding antecedents, identification, and outcomes of global citizenship at the beginning and end of a college semester course. Additionally, participants were asked to rate their perception that the class fostered greater awareness of how the world operates at the end of the semester. Unless otherwise noted, all measures used a 7-point Likert-type response scale, from $1=$ strongly disagree to $7=$ strongly agree.

\subsection{Materials}

\subsubsection{Class Global Awareness}

Five items (e.g., "This class encourages students to understand how the world works culturally") regarding the class' economic, social, cultural, technological, and environmental components were combined to assess the extent that students perceived the class to engender greater awareness of the world $(\alpha=.89)$.

\subsubsection{Global Citizenship}

Measures of antecedents, identification, and outcomes of global citizen were identical to those utilized in Study 1. All of the measures showed adequate reliability, including normative environment (pre- $\alpha=.81$, post- $\alpha=.84$ ), global awareness (pre- $\alpha=.81$, post- $\alpha=.85$ ), global citizenship identification (pre- $\alpha=.91$, post- $\alpha=.94$ ), intergroup empathy (pre- $\alpha=.82$, post- $\alpha=.83$ ), valuing diversity (pre- $\alpha=.86$, post- $\alpha=.85$ ), social justice (pre- $\alpha=.73$, post- $\alpha=.72$ ), environmental sustainability (pre- $\alpha=.75$, post- $\alpha=.83$ ), intergroup helping (pre- $\alpha$ $=.75$, post- $\alpha=.77$ ), and responsibility to act (pre- $\alpha=.73$, post- $\alpha=.85$ ).

\section{Results}

\subsection{Preliminary Analyses}

To examine the relationship between perception of the class and change in assessed global citizenship measures, the researchers constructed difference scores (post-test minus pre-test) and conducted zero-order correlations. As shown in Table 3, the perception of the class as encouraging greater understanding of world was positively and significantly correlated with increases on the global citizenship measures during the college semester. Furthermore, increases in the antecedents, identification, and outcomes of global citizenship were significantly positively correlated with one another.

Table 3. Correlations between perception of class and antecedents, identification, and outcomes of global citizenship change over college semester, Study 2 (All correlations are significant at $p<.01$. Positive difference scores represent increase in variable over college semester)

\begin{tabular}{lllllllllll}
\hline Variable & 1 & 2 & 3 & 4 & 5 & 6 & 7 & 8 & 9 & 10 \\
\hline 1. Class Environment & 1.0 & & & & & & & & & \\
2. $\Delta$ Normative Environment & .27 & 1.0 & & & & & & & & \\
3. $\Delta$ Global Awareness & .22 & .25 & 1.0 & & & & & & & \\
4. $\Delta$ Global Citizenship & .26 & .67 & .32 & 1.0 & & & & & & \\
5. $\Delta$ Intergroup Empathy & .17 & .22 & .35 & .24 & 1.0 & & & & & \\
6. $\Delta$ Valuing Diversity & .16 & .22 & .46 & .25 & .29 & 1.0 & & & & \\
7. $\Delta$ Social Justice & .19 & .24 & .23 & .24 & .21 & .30 & 1.0 & & & \\
8. $\Delta$ Environmentalism & .18 & .20 & .32 & .17 & .32 & .35 & .40 & 1.0 & & \\
9. $\Delta$ Intergroup Helping & .20 & .21 & .40 & .19 & .44 & .37 & .37 & .43 & 1.0 & \\
10. $\Delta$ Responsibility to Act & .22 & .27 & .50 & .28 & .37 & .44 & .34 & .41 & .51 & 1.0 \\
\hline Mean & 5.41 & 0.26 & 0.32 & 0.28 & 0.19 & 0.14 & 0.07 & 0.08 & 0.01 & 0.15 \\
Standard Deviation & 1.25 & 1.39 & 1.09 & 1.35 & 1.29 & 1.22 & 1.21 & 1.14 & 1.20 & 1.17 \\
\hline
\end{tabular}




\subsection{Structural Equation Model}

To test the influence of perception of the class on the antecedents, identification, and outcomes of global citizenship, the researchers conducted a structural equation model using Amos 19 (bias-corrected bootstrapping, 5,000 iterations, $95 \%$ confidence intervals). Due to the related nature of the prosocial values to one another (and the antecedents to one another), the disturbance terms for these sets of variables were allowed to covary. The pre-test variable item error terms were allowed to covary with equivalent post-test item error terms (to control for measurement error). Two error terms for global awareness (pre and post-test) and two error terms for the perception of the class were allowed to covary. Lastly, pre-test latent variables and the students' perception of the class were allowed to covary, and the pre-test latent variable covaried with the equivalent post-test latent variable (to control for students' ratings at the beginning of semester).

Items loaded well on each of the factors, including perception of the class (.61 to .87), normative environment (pre: .77, .86; post: $.82, .88$ ), global awareness (pre: .53 to .89 ; post: .61 to .90 ), global citizenship identification (pre: .90, .94; post: .94, 94), intergroup empathy (pre: .81, .87; post: .77, .91), valuing diversity (pre: .85, .88; post: $.85, .86$ ), social justice (pre: $.74, .77$; post: .75, .76), environmental sustainability (pre: $.73, .82$; post: $.80, .89$ ), intergroup helping (pre: $.78, .80$; post: $.78, .82$ ), and responsibility to act (pre: $.76, .78$; post: $.83, .88)$. The predicted model adequately fit the data, $\chi^{2}(842)=2521.10, p<.001$; RMSEA $=.050$, $\mathrm{CI}\{.048 ; .052\}, \mathrm{NFI}=.906, \mathrm{CFI}=.935$.

As shown in Figure 2, pre-test latent variables significantly predicted the equivalent post-test latent variables. While controlling for students' attitudes at the beginning of the semester, the perception of the class predicted greater normative environment $(\beta=.37, p<.001, \mathrm{CI}=.288$ to .446$)$ and global awareness $(\beta=.33, p<.001, \mathrm{CI}$ $=.251$ to .409$)$ at the end of the semester. Post-test ratings of normative environment $(\beta=.68, p=.001$, CI $=.601$ to .751$)$ and global awareness $(\beta=.22, p<.001, \mathrm{CI}=.148$ to .298$)$ predicted global citizenship identification. Post-test ratings of global citizenship identification predicted intergroup empathy $(\beta=.35, p$ $<.001, \mathrm{CI}=.282$ to .429$)$, valuing diversity $(\beta=.46, p<.001, \mathrm{CI}=.386$ to .527$)$, social justice $(\beta=.36, p$ $<.001, \mathrm{CI}=.281$ to .437$)$, environmental sustainability $(\beta=.32, p<.001, \mathrm{CI}=.253$ to .393$)$, intergroup helping $(\beta=.37, p<.001, \mathrm{CI}=.297$ to .442$)$, and felt responsibility to act $(\beta=.50, p<.001, \mathrm{CI}=.426$ to .570$)$.

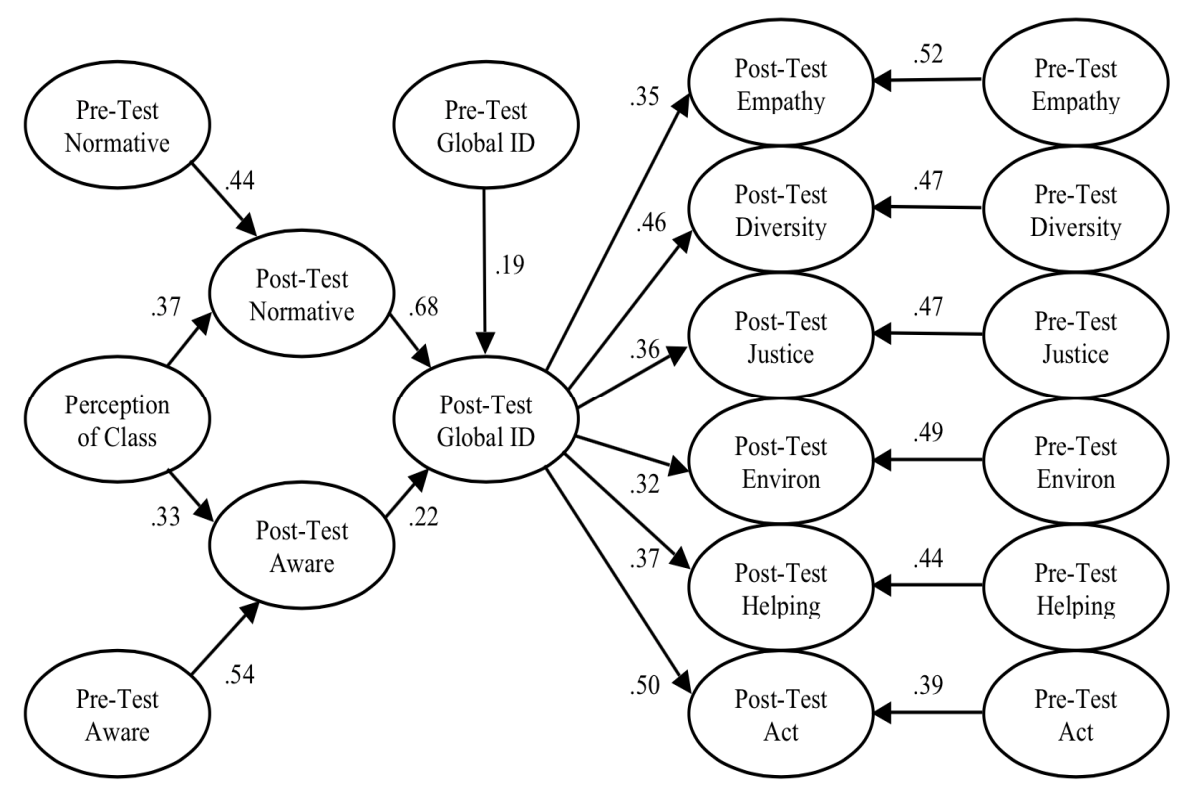

Figure 2. Influence of perception of a class as encouraging understanding of the world on global citizenship, Study 2 (All standardized betas are significant at $p<.002$ )

The indirect effect of perception of the class was reliably carried by post-test ratings of normative environment and global awareness on students' identification with global citizens (see Table 4 for standardized betas of indirect effects and 95\% bias-corrected confidence intervals; all indirect effects were significant at $p<.001$ 
two-tailed). The perception of the class also significantly predicted greater prosocial values through post-test ratings of normative environment, global awareness, and global citizenship identification. The influence of post-test normative environment and global awareness on prosocial values (e.g., social justice) was reliably carried by global citizenship identification. In effect, the perception of the class as encouraging a greater understanding of the world predicted greater normative environment and global awareness leading to greater identification with global citizens and a subsequent increase in prosocial values (controlling for self-reported ratings at the beginning of the semester and measurement error). We also tested the model including participants' biological sex and age as covariates. The model was largely unchanged by including these demographic variables.

Table 4.Indirect effects of perception of class as raising awareness, normative environment, and global awareness, Study 2 (Standardized betas and 95\% confidence intervals, bias-corrected bootstrapping with 5,000 iterations, all indirect effects are significant at $p<.001$ )

\begin{tabular}{llllllllll}
\hline \multirow{2}{*}{ Variable } & \multicolumn{3}{l}{ Class Environment } & \multicolumn{3}{c}{ Normative Environment } & \multicolumn{3}{c}{ Global Awareness } \\
\cline { 2 - 10 } & Indirect & $\mathrm{CI}_{\text {Lower }}$ & $\mathrm{CI}_{\text {Upper }}$ & Indirect & $\mathrm{CI}_{\text {Lower }}$ & $\mathrm{CI}_{\text {Upper }}$ & Indirect & $\mathrm{CI}_{\text {Lower }}$ & $\mathrm{CI}_{\text {Upper }}$ \\
Global Citizenship ID & .32 & .257 & .386 & & & & & & \\
Intergroup Empathy & .11 & .080 & .157 & .24 & .186 & .301 & .08 & .049 & .118 \\
Valuing Diversity & .15 & .109 & .193 & .31 & .257 & .367 & .10 & .064 & .149 \\
Social Justice & .12 & .081 & .156 & .24 & .187 & .304 & .08 & .049 & .119 \\
Environmentalism & .10 & .074 & .141 & .22 & .171 & .274 & .07 & .045 & .108 \\
Intergroup Helping & .12 & .086 & .159 & .25 & .200 & .311 & .08 & .052 & .122 \\
Responsibility to Act & .16 & .120 & .208 & .34 & .281 & .398 & .11 & .072 & .162 \\
\hline
\end{tabular}

\section{Discussion}

\subsection{Study 2 Discussion}

Study 2 examined the effect of students' perception that a specific college course fostered greater global awareness on the antecedents, identification, and outcomes of global citizenship. The results indicate that students' perception that the course encouraged a greater understanding of the world predicted greater normative environment and global awareness, which predicted greater identification with global citizens and subsequently predicts prosocial values.

\subsection{General Discussion}

The purpose of the present set of studies was to examine the influence of the university environment and class curriculum on the antecedents, identification, and outcomes of global citizenship. As predicted, students' perception that their university encourages global citizenship (Study 1) and the perception that a college course increased one's level of global awareness (Study 2) influenced the model of antecedents and outcomes of global citizenship identification. The results show that the environments in which students are embedded can influence global citizenship identification (through one's normative environment and global awareness) and prosocial values and behaviors (through the antecedents and global citizenship identification). Together, the results highlight the impact that both the general university environment and the curriculum in particular can have on engendering prosocial values and behaviors.

Supporting past theorizing (Dower, 2008; Hicks, 2003; Oxfam, 1997; Pike, 2008; Schattle, 2008; Young \& Commins, 2002), the present results show that educational settings can be a supportive place for fostering global citizenship. Everyday environments, such as educational settings, are infused with culturally meaningful and socially constructed patterns that afford individuals the opportunity to identify with various identities and can condition and prime those identities (see Adams \& Markus, 2004; Shweder, 1990). As shown in Study 1, the perception that one's university encouraged a global citizen identity strongly influenced how students perceived valued others in their life (i.e., normative environment) and their perceived knowledge and connection to the world (i.e., global awareness). The downstream influence then affected students' identity and endorsement of prosocial values. Further research is needed to examine additional aspects of the educational environment that 
may lend to the socio-cultural setting that promotes a global citizen identity. Prior studies have shown that both college administrators (Snider et al., 2013) and faculty (Gibson \& Reysen, 2013) can influence global citizenship identification. However, there may be a variety of implicit influences that lead to an atmosphere promoting a global perspective (e.g., presence of diverse student body, symbols of the world in displays on university walls). One source of promotion of global citizen identity is the curriculum that instructors choose to include in classes.

Building from the indirect link identified between curriculum and global citizenship identification (i.e., university classes with syllabi containing words related to global citizenship predicted greater identification at the end of the semester) (Reysen et al., 2012), the researchers directly assessed students' perception that a specific college course encouraged greater global awareness in Study 2. Past research has shown a causal relationship between students' perception of their global awareness and identification (Reysen et al., 2013),therefore the researchers predicted, and found, that as students perceived the class as fostering increased learning about the world, the model of antecedents and outcomes of global citizenship identification was influenced. A next step for researchers is to more closely examine specific aspects of the curriculum that might encourage global awareness. Interestingly, the researchers' assessment of students in a variety of different academic domains (e.g., psychology, education, political science, English, business, marketing) suggested that curriculum can include global perspectives regardless of course topic. As universities struggle to implement and assess global citizen programs (see Sperandio, Grudzinski-Hall, \& Stewart-Gambino, 2010), the present results suggest that assessing perception of the class as raising global awareness is a measure that may be fruitfully adapted across academic domains. As shown in Study 2, regardless of students' attitudes at the beginning of the semester, increased perception of the class as encouraging greater understanding of the world influenced their global citizenship identification and prosocial values.

\section{Study Limitations}

Although the present set of studies is novel in highlighting the influence of the university environment (Study 1), and specific college courses (Study 2), on the antecedents and outcomes of global citizenship identification, there are limitations that should be considered when interpreting the results.Specifically, participants in the present study consisted of college students attending a single university in the United States. Significant differences have been identified across populations and cultures on a variety of psychological and behavioral measurements (Henrich, Heine, \& Norenzayan, 2010). However, similar patterns of association between identification as a global citizen and endorsement of prosocial values have been found in participants sampled in other countries (Katzarska-Miller et al., 2012) and older adults sampled outside the university (Plante et al., 2014). Furthermore, although we strived to sample students across a wide variety of academic domains (e.g., business, psychology, health), the results may differ with different sampling techniques or other participant populations.Although the present studies results are consistent with the growing body of empirical evidence (Gibson \& Reysen, 2013; Reysen et al., 2013; Reysen et al., 2012), caution should be taken in over-generalizing the results. The results are correlational, and therefore, do not indicate a cause and effect relationship. Lastly, the model presented, while well supported by prior studies, may include other antecedents and outcomes that were not measured.

\section{Conclusion}

As researchers continue to explore the beneficial outcomes of viewing the self as a member of the world (e.g., McFarland, 2011) greater attention has been focused on the construction of the educational environment (see Sperandio et al., 2010). In the present studies, the university environment and class presentation of global topics were shown to influence students' degree of global citizenship identification leading to greater endorsement of prosocial values. Identification as a global citizen, and the increased endorsement of prosocial values that result, may be beneficial in cross-cultural interaction and understanding, which are considered as important for effective functioning in an increasingly interconnected and globalized world.

\section{References}

Adams, G., \& Markus, H. R. (2004). Toward a conception of culture suitable for a social psychology of culture. In M. Schaller, \& C. S. Crandall (Eds.), The psychological foundations of culture (pp. 335-360). Mahwah, NJ: Lawrence Erlbaum Associates.

Browne, M. W., \& Cudeck, R. (1993). Alternative ways of assessing model fit. In K. A. Bollen, \& J. S. Long (Eds.), Testing structural equation models (pp. 136-162). Newbury Park, CA: Sage. 
Dower, N. (2008). Are we all global citizens or only some of us are global citizens? In A. Abdi, \& L. Shultz (Eds.), Educating for human rights and global citizenship (pp. 39-53). Albany, NY: State University of New York Press.

Fujikane, H. (2003). Approaches to global education in the United States, the United Kingdom, and Japan. International Review of Education, 49, 133-152. http://dx.doi.org/10.1023/A:1022994613635

Gacel-Avila, J. (2005).The internationalisation of higher education: A paradigm for global citizenry. Journal of Studies in International Education, 9, 121-136. http://dx.doi.org/10.1177/1028315304263795

Gelfand, M. J., Lyons, S. L., \& Lun, J. (2011). Toward a psychological science of globalization. Journal of Social Issues, 67, 841-853. http://dx.doi.org/10.1111/j.1540-4560.2011.01731.x

Gibson, S. A., \& Reysen, S. (2013). Representations of global citizenship in a school environment. International Journal of Education Research, 8(1), 116-128.

Gollnick, D. M., \& Chinn, P. C. (2013). Multicultural Education in a Pluralistic Society (9th ed.). Upper Saddle River, NJ: Merrill-Prentice Hall.

Henrich, J., Heine, S. J., \& Norenzayan, A. (2010). The weirdest people in the world? Behavioral and Brain Sciences, 33, 62-135. http://dx.doi.org/10.1017/S0140525X0999152X

Hicks, D. (2003). Thirty years of global education: Areminder ofkey principles andprecedents. Educational Review, 55, 265-275. http://dx.doi.org/10.1080/0013191032000118929

Hu, L. T., \& Bentler, P. M. (1995). Writing about structural equation models. In R. H. Hoyle (Ed.), Structural equation modeling: Concepts, issues and applications (pp. 76-99). Thousand Oaks, CA: Sage.

Katzarska-Miller, I., Reysen, S., Kamble, S. V., \& Vithoji, N. (2012). Cross-national differences in global citizenship: Comparison of Bulgaria, India, and the United States. Journal of Globalization Studies, 3, 166-183.

McFarland, S. G. (2011). Presidential address: The slow creation of humanity. Political Psychology, 32, 1-20. http://dx.doi.org/10.1111/j.1467-9221.2010.00801.x

Merryfield, M., Lo, J., Po, S. C., \& Kasai, M. (2008). World mindedness: Taking off the blinders. Journal of Curriculum and Instruction, 2, 6-20. http://dx.doi.org/10.3776/joci.2008.v2n1p6-20

Oxfam. (1997). A curriculum for global citizenship. Oxford, UK: Oxfam.

Pike, G. (2008). Reconstructing the legend: Educating for global citizenship. In A. Abdi, \& L. Shultz (Eds.), Educating for human rights and global citizenship (pp. 39-53). Albany, NY: State University of New York Press.

Plante, C. N., Roberts, S., Reysen, S., \& Gerbasi, K. (2014). "One of us": Engagement with fandoms and global citizenship identification. Psychology of Popular Media Culture, 3(1), 49-64. http://dx.doi.org/10.1037/ ppm0000008

Reysen, S., \& Katzarska-Miller, I. (2013a). A model of global citizenship: Antecedents and outcomes. International Journal of Psychology, 48, 858-870. http://dx.doi.org/10.1080/00207594.2012.701749

Reysen, S., \& Katzarska-Miller, I. (2013b). Student pathways to global citizenship. In C. Boyle (Ed.), Student learning: Improving practice (pp. 121-137). Hauppauge, NY: Nova.

Reysen, S., \& Levine, R. V. (2014). People, culture, and place: How place predicts helping toward strangers. In P. J. Rentfrow (Ed.), Geographical psychology: Exploring the interaction of environment and behavior ( $\mathrm{pp}$. 241-260). Washington DC: APA. http://dx.doi.org/10.1037/14272-013

Reysen, S., Katzarska-Miller, I., Gibson, S. A., \& Hobson, B. (2013). World knowledge and global citizenship: Factual and perceived world knowledge as predictors of global citizenship identification. International Journal of Development Education and Global Learning, 5, 49-68.

Reysen, S., Larey, L. W., \& Katzarska-Miller, I. (2012). College course curriculum and global citizenship. International Journal of Development Education and Global Learning, 4, 27-39.

Reysen, S., Pierce, L., Spencer, C., \& Katzarska-Miller, I. (in press). Exploring the content of global citizenship identity. The Journal of Multiculturalism in Education.

Schattle, H. (2008). The practices of global citizenship. Lanham, MD: Rowman \& Littlefield. 
Shweder, R. A. (1990). Cultural psychology—what is it? In J. Stigler, R. Shweder, \& G. Herdt (Eds.), Cultural psychology: Essays on comparative human development (pp. 1-46). Cambridge, UK: Cambridge University Press. http://dx.doi.org/10.1017/CBO9781139173728.002

Snider, J. S., Reysen, S., \& Katzarska-Miller, I. (2013). How we frame the message of globalization matters. Journal of Applied Social Psychology, 43, 1599-1607. http://dx.doi.org/10.1111/jasp.12111

Sperandio, J., Grudzinski-Hall, M., \& Stewart-Gambino, H. (2010). Developing an undergraduate global citizenship program: Challenges of definition and assessment. International Journal of Teaching and Learning in Higher Education, 22, 12-22.

Spring, J. (2008). Research on globalization and education. Review of Educational Research, 78, 330-363. http://dx.doi.org/10.3102/0034654308317846

Tajfel, H., \& Turner, J. C. (1979). An integrative theory of intergroup conflict. In W. Austin, \& S. Worchel (Eds.), The social psychology of intergroup relations (pp. 33-47). Monterey, CA: Brooks/Cole.

Turner, J. C., Hogg, M. A., Oakes, P. J., Reicher, S. D., \& Wetherell, M. (1987). Rediscovering the social group: A self-categorization theory. Oxford: Blackwell.

Young, M., \& Commins, E. (2002). Global citizenship: The handbook for primary teaching. Oxford, UK: Oxfam.

\section{Copyrights}

Copyright for this article is retained by the author(s), with first publication rights granted to the journal.

This is an open-access article distributed under the terms and conditions of the Creative Commons Attribution license (http://creativecommons.org/licenses/by/3.0/) 